\title{
A CRITERION FOR P-VALENTLY STARLIKE FUNCTIONS
}

\section{SHIGEYOSHI OWA}

Department of Mathematics

Kinki University

Higashi-Osaka, Osaka 577, Japan

\section{MAMORU NUNOKAWA}

Department of Mathematics Gunma University

Aramaki, Maebashi, Gunma 371, Japan
SEIICHI FUKUI

Department of Mathematics

Wakayama University Wakayama 640, Japan

(Received December 22, 1992 and in revised form April 19, 1993)

ABSTRACT. The object of the present paper is to prove a criterion for $p$-valently starlike functions in the open unit disk.

KEY WORDS AND PHRASES. Analytic, open unit disk, $p$-valently starlike.

1991 AMS SUBJECT CLASSIFICATION CODE. Primary, 30C45.

\section{INTRODUCTION.}

Let $A(p)$ be the class of functions of the form

$$
f(z)=z^{p}+\sum_{n=p+1}^{\infty} a_{n} z^{n} \quad(p \in N=\{1,2,3, \cdots\})
$$

which are analytic in the open unit disk $U=\{z:|z|<1\}$. A function $f(z)$ belonging to $A(p)$ is said to be $p$-valently starlike in $U$ if it satisfies

$$
\operatorname{R}\left\{\frac{z f^{\prime}(z)}{f(z)}\right\}>0 \quad(z \in U) .
$$

We denote by $S(p)$ the subclass of $A(p)$ consisting of functions $f(z)$ which are $p$-valently starlike in $U$ (cf. [1]).

Recently, Nunokawa [4] has shown that

THEOREM A. If $f(z) \in A(p)$ satisfies $f(z) \neq 0(0<|z|<1)$ and

$$
\operatorname{Re}\left\{\frac{1+\frac{z f^{\prime \prime}(z)}{f^{\prime}(z)}}{\frac{z f^{\prime}(z)}{f(z)}}\right\}<1+\frac{1}{2 p} \quad(z \in U)
$$

then $f(z) \in S(p)$.

In the present paper, we derive a new criterion for the class $S(p)$ involving the above result by Nunokawa [4].

\section{A NEW CRITERION.}

To derive our main result, we have to recall here the following lemma due to Jack [2] (also, due to Miller and Mocanu [3]).

LEMMA. Let $w(z)$ be analytic in $U$ with $w(0)=0$. If $|w(z)|$ attains its maximum value on the circle $|z|=r<1$ at a point $z_{0}$, then we can write

$$
z_{0} w^{\prime}\left(z_{0}\right)=k w\left(z_{0}\right)
$$

where $k$ is a real number and $k \geqq 1$. 
Now, we prove

THEOREM. If $f(z) \in A(p)$ satisfies $f(z) \neq 0(0<|z|<1)$ and

$$
\left|\arg \left\{\frac{f(z)}{z f^{\prime}(z)}\left(1+\frac{z f^{\prime \prime}(z)}{f^{\prime}(z)}\right)-\left(1+\frac{1}{4 p}\right)\right\}\right|>0 \quad(z \in U),
$$

then $f(z) \in S(p)$ and

$$
\left|\frac{z f^{\prime}(z)}{f(z)}-p\right|<p \quad(z \in U) .
$$

PROOF. Define the function $w(z)$ by

$$
\frac{z f^{\prime}(z)}{f(z)}=p(1+w(z))
$$

Then $w(z)$ is analytic in $U$ and $w(0)=0$. It follows from (2.4) that

so that,

$$
1+\frac{z f^{\prime \prime}(z)}{f^{\prime}(z)}=p(1+w(z))+\frac{z w^{\prime}(z)}{1+w(z)}
$$

$$
\frac{f(z)}{z f^{\prime}(z)}\left(1+\frac{z f^{\prime \prime}(z)}{f^{\prime}(z)}\right)=1+\frac{z w^{\prime}(z)}{p(1+w(z))^{2}}
$$

Suppose that there exists a point $z_{0} \in U$ such that

$$
|z| \leqq\left|z_{0}\right| \quad|w(z)|=\left|w\left(z_{0}\right)\right|=1 \quad\left(w\left(z_{0}\right) \neq-1\right) .
$$

Then, applying Lemma, we can write

$$
z_{0} w^{\prime}\left(z_{0}\right)=k w\left(z_{0}\right) \quad(k \geqq 1)
$$

and $w\left(z_{0}\right)=e^{i \theta}(\theta \neq \pi)$. Thus we have

$$
\begin{gathered}
\frac{f\left(z_{0}\right)}{z_{0} f^{\prime}\left(z_{0}\right)}\left(1+\frac{z_{0} f^{\prime \prime}\left(z_{0}\right)}{f^{\prime}\left(z_{0}\right)}\right)=1+\frac{k e^{i \theta}}{p\left(1+e^{i \theta}\right)^{2}} \\
=1+\frac{k}{2 p(1+\cos \theta)} \\
\geqq 1+\frac{1}{4 p} .
\end{gathered}
$$

Note that the condition (2.2) implies

$$
\frac{f(z)}{z f^{\prime}(z)}\left(1+\frac{z f^{\prime \prime}(z)}{f^{\prime}(z)}\right) \neq \alpha \quad(z \in U),
$$

where $\alpha \geqq 1+1 / 4 p$. Therefore, (2.7) contradicts our condition (2.2). Consequently, we conclude that

$$
\left|\frac{z f^{\prime}(z)}{f(z)}-p\right|<p \quad(z \in U)
$$

that is, that $f(z) \in S(p)$.

Letting $p=1$ in Theorem, we have

COROLLARY. If $f(z) \in A(1)$ satisfies $f(z) \neq 0(0<|z|<1)$ and

$$
\mid \arg \left\{\frac{f(z)}{z f^{\prime}(z)}\left(1+\frac{z f^{\prime \prime}(z)}{f^{\prime}(z)}\right)-\frac{5}{4} \mid>0 \quad(z \in U),\right.
$$

then $f(z) \in S(1)$ and

$$
\left|\frac{z f^{\prime}(z)}{f(z)}-1\right|<1 \quad(z \in U)
$$


ACKNOWLEDGEMENT. The research of the first author was supported in part by Japanese Ministry of Education, Science and Culture under Grant-in-Aid for General Scientific Research (No. 04640204).

\section{REFERENCES}

1. GOODMAN, A.W., On the Schwarz-Christoffel transformation and p-valent functions, Trans. Amer. Math. Soc. 68, (1950), 204-223.

2. JACK, I.S., Functions starlike and convex of order $\alpha$, J. London Math. Soc. 3 (1971), 469474.

3. MILLER, S.S. \& MOCANU, P.T., Second order differential inequalities in the complex plane, J. Math. Anal. Appl. 65 (1978), 289-305.

4. NUNOKAWA, M., Certain class of starlike functions, to appear. 


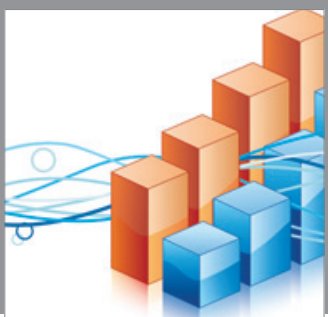

Advances in

Operations Research

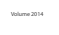

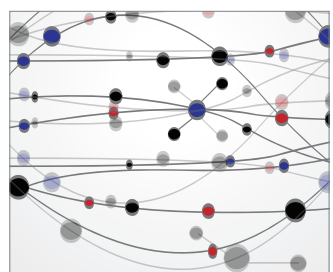

\section{The Scientific} World Journal
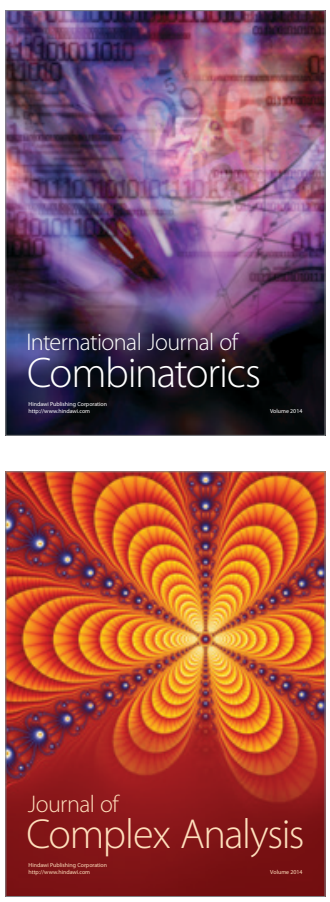

International Journal of

Mathematics and

Mathematical

Sciences
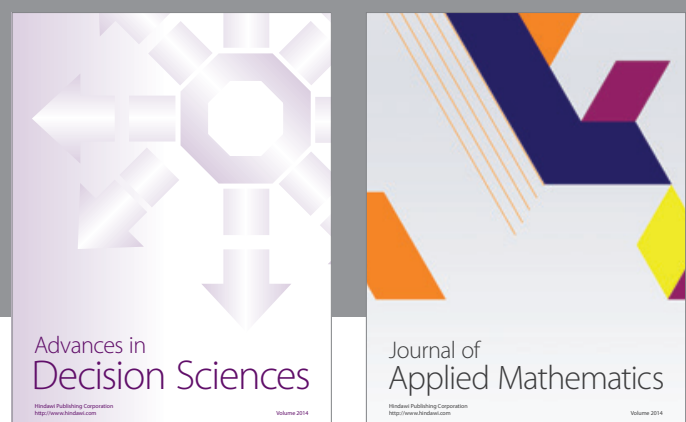

Journal of

Applied Mathematics
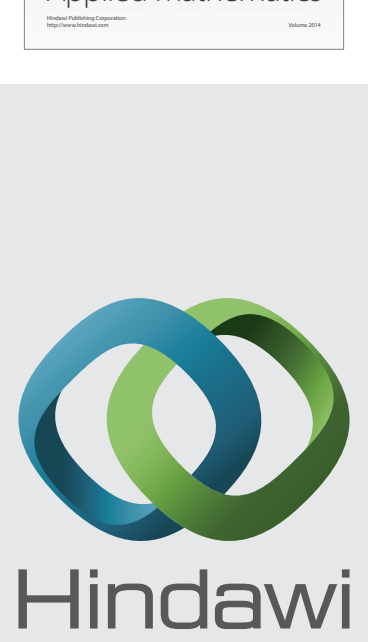

Submit your manuscripts at http://www.hindawi.com
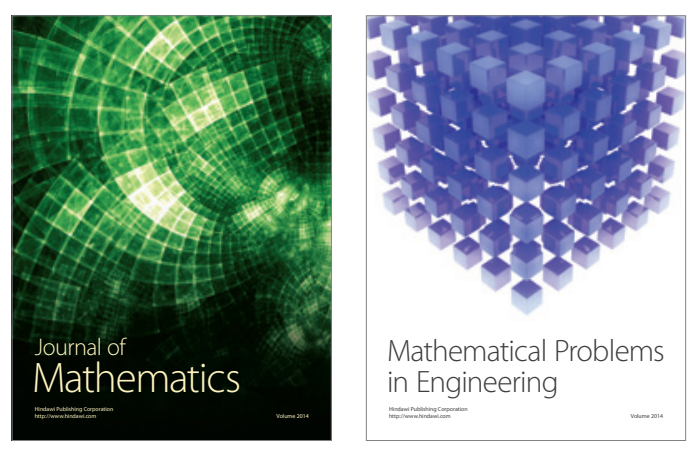

Mathematical Problems in Engineering
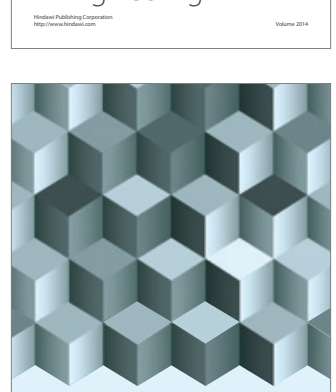

Journal of

Function Spaces
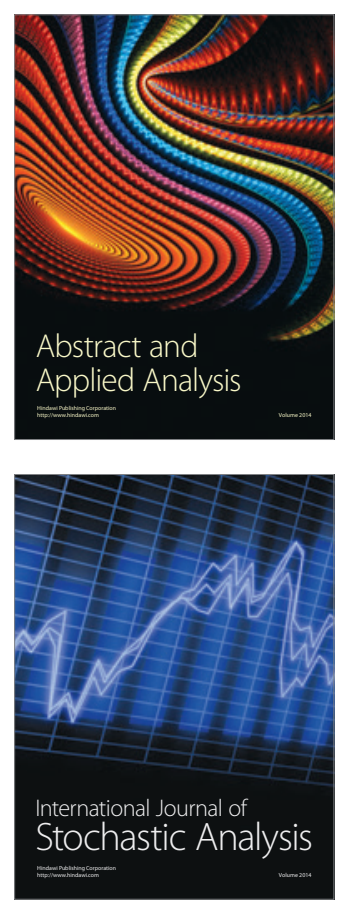

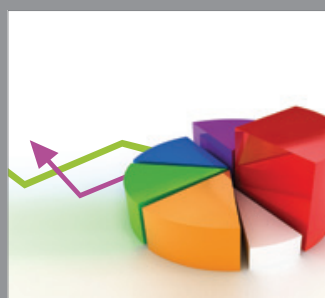

ournal of

Probability and Statistics

Promensencen
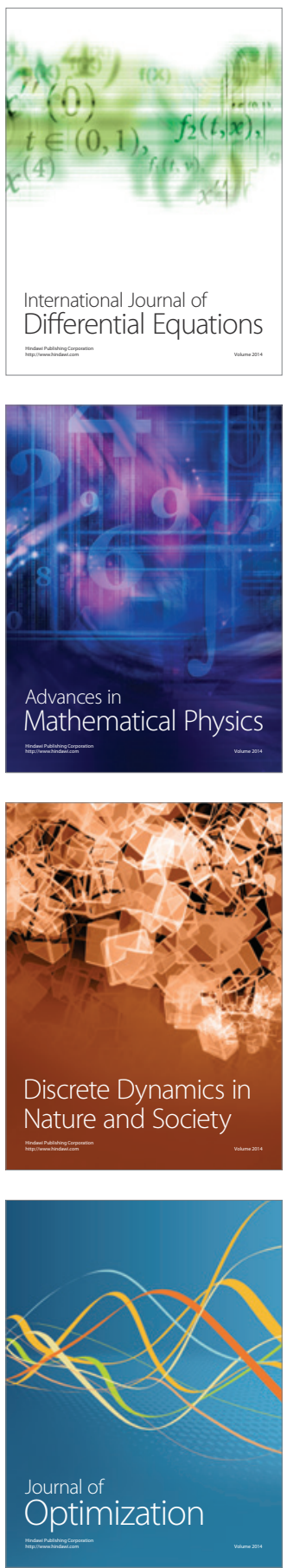